NEWS

\title{
Nuclear renaissance plans hit by financial crisis
}

\author{
Role of fission in fighting climate change looks likely to wane.
}

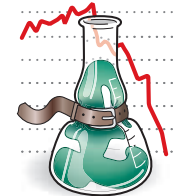

WATCH
RECESSION

Frozen global credit markets and the prospect of a prolonged economic recession are threatening the resurgence of nuclear power that has been touted by governments and industry around the world.

The growing difficulties in attracting investment may prevent nuclear power from playing a significant role in the fight against climate change. A global energy outlook published on 12 November by the International Energy Agency, an intergovernmental organization that guides energy policy, called for an $80 \%$ increase in the world's current nuclear capacity by 2030 in order to keep global carbon dioxide levels from rising above 450 parts per million.

That would require bringing some 25 new reactors online every year between now and 2030 , five times the current rate of construction, according to Matthew Bunn, a nuclear-policy expert at Harvard University. Given the bleak financial outlook and the limited production capabilities of power-plant vendors, "nuclear can no longer support climate-change needs and targets", he says.

The global downturn means that many utility companies will be "pressing the pause button" on new nuclear plans, says John Gilbertson, who tracks financing for nuclear projects as a managing director for the New York-based brokerage firm Goldman Sachs. "Markets right now are less receptive and capital is more expensive," he says. "Every one of these companies is going through a massive gut-check." Indeed, the French nuclear supplier Areva has told Nature that it expects orders for new nuclear power stations to slow, particularly in the United States, where utility companies have applied to the government's Nuclear Regulatory Commission to build seven Areva reactors. But those have yet to translate into confirmed orders with the French company.

Even before the crisis, commercial financing was probably not available in the United States "at any price" without some government incentives, according to Joe Turnage, a senior vice-president for strategy at UniStar Nuclear
Energy, a consortium seeking to build new nuclear plants in Maryland, Pennsylvania and New York state.

But what was a tough task before the downturn is becoming almost impossible in the global recession, according to Mycle Schneider, an independent nuclear consultant based in Paris. Nuclear-parts suppliers are unlikely to expand production, and private utility companies - which must provide billions in investment for new plant construction - have seen their stocks battered in recent weeks. Together with a shortage of skilled labour, the slowdown means that over the next decade "the industry will not even be able to replace the units being shut down because of ageing", predicts Schneider.

\section{Missing targets}

The bleak economic outlook makes it even less likely that nuclear will contribute to meeting governments' greenhouse-gas emission targets.

Britain, for example, is about to establish in law a commitment to an $80 \%$ reduction in greenhouse-gas emissions, compared with 1990 levels, by 2050 (see Nature 456, 13; 2008). To achieve hose figures would require roughly doubling the current number of nuclear plants in Britain to about 40 by 2025 , according to David King, director of the Smith School of Enterprise and the Environment at the University of Oxford, $\mathrm{UK}$, and formerly UK chief scientific adviser.

King believes the target is still achievable, but John Large, an independent, Londonbased nuclear consultant, disagrees. The shortages in nuclear-plant components created by the downturn will make a radical expansion impossible, he predicts. Consequently, "I suspect we're going to miss our carbon targets".

The outlook, of course, varies from country to country. Some developing nations, notably China, are rolling out major expansions in nuclear capacity. China is planning to more than quadruple its present nuclear output, with a stated goal of 40 gigawatts of installed capacity by 2020 . Because this is funded directly by the government, it is less likely to be affected by the current credit crunch.

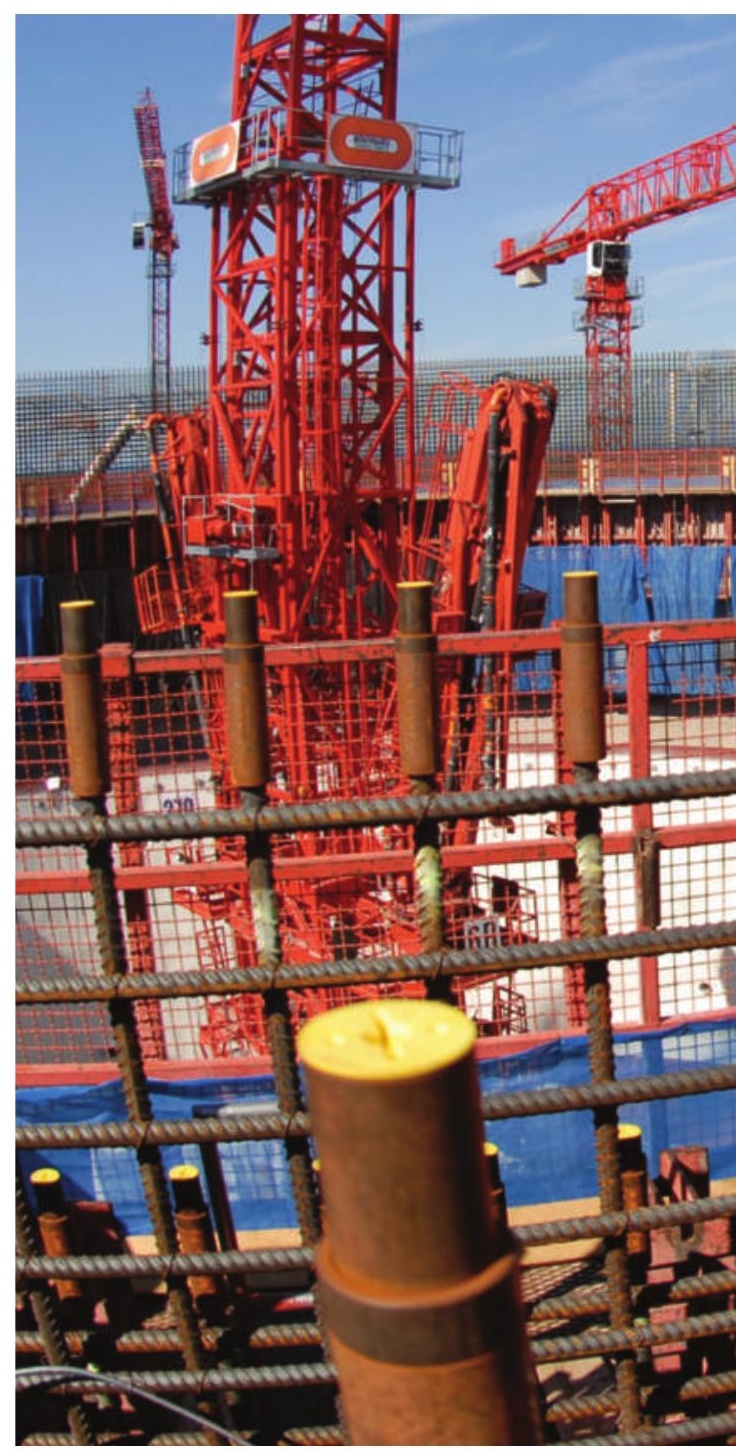

But in many other countries where power markets are in various stages of deregulation, utilities must raise billions from investors to build a new plant, even though they are being helped by subsidies and incentives from governments.

With private investors running scared, government financing is becoming ever more vital. For example, the United States Enrichment Corporation (USEC), which enriches uranium fuel for nuclear reactors, announced on 4 November that the credit crunch may force it to delay opening the US\$3.5-billion American Centrifuge Plant in Piketon, Ohio. The plant is one of the few nuclear facilities in the United States that is currently under construction, and was expected to begin operation in 2010.

Although the company was hoping to receive federal loan guarantees, it was also seeking private investment in the project. "The credit market situation simply makes that more 
